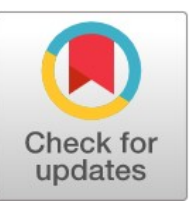

PRIMARY RESEARCH

\title{
Using ontology for goal-based query to evaluate social media data
}

\author{
Tengku Adil Tengku Izhar ${ }^{1,}{ }^{*}$ Mohammad Fazli Baharuddin ${ }^{2}$, Ahmad Nadzri Mohamad ${ }^{3}$, Ahmad \\ Azman Mohamad Ramli ${ }^{4}$, Mohd Shamsul Mohd Shoid ${ }^{5}$, Wan Mohd Hafiz Wan Hasnol ${ }^{6}$ \\ 1, 2, 3, 4, 5 Faculty of Information Management, Universiti Teknologi MARA (UiTM) Selangor, Malaysia \\ ${ }^{6}$ Faculty of Information Management, Universiti Teknologi MARA (UiTM) Kedah Campus, Kedah, \\ Malaysia
}

\section{Keywords:}

Big data

Decision-making

Goal

Ontology

Query

Social media

Received: 8 March 2016

Accepted: 12 March 2016

Published: 26 April 2016

\begin{abstract}
This paper aims to structure big data to set up a goal based on ontology to show the dependency relationship between social data and GI. At this research stage, user trends on social media are being examined based on a certain query as this query is defined as a goal. NodeXL is used to obtain and analyze data from Twitter. The results discuss the relationship for data from Twitter in relation to the specific goal. The outcome of this paper will contribute to a significant achievement that provides an important innovation in research methods in the big data era to trace how data flows across social media and how to analyze this data. This research extends the application of the ontology for social media concerning the goal by developing the relationship for this social data.
\end{abstract}

(C) 2016 The Author(s). Published by TAF Publishing.

\section{INTRODUCTION}

Today, there are tons of data collected from devices all over the world. Devices such as mobile phones, laptops, tablets and even video games such as Play Stations are connected to the Internet. These devices transmitted millions of data everywhere in the world and it highlights the development of big data. Billions of devices will be connected to the Internet and soon hundreds of billions of devices. As these devices are connected to each other, these connected devices become an intelligent system of systems. Intelligent system of systems can share data and analyze it over cloud and they can transform our businesses, our lives and our world in countless ways. For example, improving the medical outcomes and building better products faster with lower development cost.

Nothing in technology stands still especially in the world of data and analytics. Systems built just a few years ago are starting to buckle under the explosion of data and the changing query needs of business users. Social media

\footnotetext{
* Corresponding author: Tengku Adil Tengku Izhar

E-mail: tengkuadil@yahoo.co.uk
} 
have now become an important medium of communication and interaction tools for social networks (Ghani and Siti Syahidah, 2015). Social media are also important for business platform that can influence the corporative environment (Damianos et al. 2011; Domianos et al. 2007; Holtzblatt et al. 2013). For example, social networks involve agents in creating and processing information for knowledge network (Roth and Jean-Philippe, 2010). At the same time, the role that causality can play in social network analysis is unclear (Doreian, 2001). Therefore, it is important to examine the flow of data in social media and to retrieve relevant data from large amount of it. In this paper, an ontology is applied to develop the relationship of data in social media. This relationship is important to capture data that can be considered relevant for certain query.

Firms and other organizations have been using large databases and analytics for the last couple of decades. Transactions are stored in data warehouses and analyzed with data-mining algorithms to extract insights (Galbraith, 2014). Taking advantage of big data opportunities is a challenge for organizations (Berber et al. 2014). In order to ensure the effectiveness of the data, organization needs to be able to store data reliably across a number of databases. Once data need to be distributed, organizations need a way to get it out again and they need to identify which data is needed, assemble it and analyze it. The challenge is how to capture this data to be considered relevant for the specific organization activities because determining relevant data is a key to delivering value from massive amounts of data. The real issue is not how the organizations acquire large amount of data but what they do with the data that count (Davenport and Jill, 2013). Having an ability to analyze the data in a timely fashion can ensure a competitive edge for efficient decision-making. However, the trustworthiness of data in relation to the goals is often questionable due to the huge amount of data especially from social media. The technologies and concepts behind big data can allow us to achieve a variety of objectives.

Ontology works as a type of relationship to represent the dependency relationship of data from the datasets and dependency relationship between data and goal. Despite the various existing methodologies on ontology (Fox et al. 1996; Fox et al. 1998; Mansingh et al. 2009; Rao et al. 2012; Rao et al. 2009; Sharma and Kweku-Muata, 2008), there are many opportunities that need to be explored. The aim of this paper focuses on structuring the big data to set up a goal based on ontology to show the dependency relationship between social data and goal. The process consists of identifying which data are relevant to the goal. The paper examines user trends on social media based on certain query as this query is defined as a goal. The process is expected to increase precise relevant information from social media content. The research will make significant achievement that provides an important innovation in research methods in big data era to trace how data flows across the social media and how to analyze this data. Big data require increasingly more advanced capabilities to find patterns in the inherent complexity for certain goal.

The ideas of using an ontology and visual structuring in organization applications were discussed in many works and now are implemented in many sectors (Almeida and Ricardo, 2009; Mansingh et al. 2009; Rao et al. 2012; Valaski et al. 2012). However, much of the research in this field did not receive much attention in the literature that incorporates big data for social media by setting up a query as a goal. An ontology provides explicit and formal specifications of 
knowledge, especially implicit or hidden knowledge (Cho et al. 2006). By incorporating the big data, an ontology makes the process to identify the relevance of data more easily consumable to address which data from the datasets are more important to evaluate certain goal.

The remainder of this paper is organized as follows. Section 2 is literature review. Section 3 is methodology. Section 4 is the case study. The final section contains some concluding remarks.

\section{LITERATURE REVIEW}

In recent years, the rapid development of Internet, Internet of Things, and Cloud Computing have led to the explosive growth of data in almost every industry and business area. Big data have rapidly developed into a hot topic that attracts extensive attention from academia, industry, and governments around the world. There are many challenges in harnessing the potential of big data today, ranging from the design of processing systems at the lower layer to analysis means at the higher layer, as well as a series of open problems in scientific research. Big data processing systems are suitable for handling a diversity of data types and applications are the key to supporting scientific research of big data (Jin et al. 2015). Social networking tools (e.g., Twitter, LinkedIn, Facebook, MySpace) have been proliferating on the internet.

Social media are transforming the way information travels within and between networks of individuals (Gangadharbatla et al. 2014). Although the research on social networks dates back to early 1920s, nevertheless, social media analytics is a nascent field that has emerged after the advent of Web 2.0 in the early 2000s. The key characteristic of the modern social media analytics is its data-centric nature. Social media analytics refer to the analysis of structured and unstructured data from social media channels. Social media is a broad term encompassing a variety of online platforms that allow users to create and exchange content. User-generated content (e.g., sentiments, images, videos, and bookmarks) and the relationships and interactions between the network entities (e.g., people, organizations, and products) are the two sources of information in social media (Gandomi and Murtaza, 2015).

Social media have profoundly changed our lives and how we interact with one another and the world around us (Qualman, 2009; Safko and Kevin, 2009). Recent research indicates that more and more people are using social media applications such as Facebook and Twitters for various reasons such as making new friends, socializing with old friends, receiving information, and entertaining themselves (Kaplan and Michael, 2010; Keckley, 2010; Park et al. 2009; Raacke and Bonds-Raacke, 2008). Social media analysis will extract value from vast amount of social media data to detect and discover new knowledge to understand how industry is changing, and use the findings and improved understanding to achieve competitive advantage against their competitors (Governatori and Renato, 2011; He et al. 2013). Social media competitive analysis allows a business to gain possible business advantage by analyzing the publicly available social media data of a business and its competitors (He et al. 2013). As social media have become a topic of interest for many industries, it is important to understand how social media data can be harvested for decision-making (He et al. 2013).

With the development of smart devices and cloud computing, more and more public data can be collected from various sources and can be analyzed in an 
unprecedented way. The huge social and academic impact of such developments caused a worldwide buzz for big data (Huang et al. 2015). Data flow is an ordered sequence, which is consecutive, high-speed, infinite and time varying. It's also of great importance in internet management, internet security and internet experiment. However, with the rapid development of internet technology, the number of internet applications and users keeps rising, and the internet data are growing exponentially (Zhi et al. 2011). There are stricter requirements about the efficiency, expandability and stability of the data flow in social media.

\section{METHODOLOGY}

\section{A Need for an Ontology}

In order to create a domain ontology, one can adopt various methods, like extending existing ontologies or developing the ontology from the ground up (Kontopoulos et al. 2013). The contribution of an ontology is to improve the creation of model that ultimately takes place through the defined goals (Izhar et al. 2013).

Ontology consists of filtering and application. Filtering is a process to filter the data from the datasets by referring to the certain query. In this paper, we refer to query as a goal. We develop the dependency relationship for this data in relation to the goal. For example, if we want to examine the number of tweets about PhD, then we will examine number of people who tweet or mention the word $\mathrm{PhD}$ in their profile. Application is a stage to use analytics to analyze the dependency relationship between data and goal. In this paper, an ontology is designed for big data to:

- be applicable in a wide range of domains,

-successfully structure the dependency relationship of data from the datasets, -successfully structure the dependency relationship between data that relate to the goal.

\section{Ontology for Goals Query}

Despite of many research efforts and established model for the evaluation of goal using an ontology (Fox et al. 1998; Izhar et al. 2013; Sharma and Kweku-Muata, 2008), they have not yet been systematically applied to set up a query as a goal for social media. In this paper, several structures that were proposed in the previous models are combined, as shown in Table 1 . These models are adapted as a reference to set up goal query based on an ontology. However, the scope of the proposed ontology in this paper does not cover all the organizational processes as discussed in Sharma and Kweku-Muata (2008), Fox et al. (1998) and Rao et al. (2012). This is because we do not focus on the organizational structure but we extend the relationship between social data and goal.

Fox et al. (1998) focused on structuring the linkage between organizational structure and behavior. This is critical for enterprise model development. However, the authors do not emphasize any organizational resources such as data and information but they focus on the roles and activities within the organization. Meanwhile, Sharma and Kweku-Muata (2008) developed a framework for an organizational ontology in an effort to increase an understanding of the business. However, the authors do not specifically identify the relationship between organizational resources, such as data and the organizational goals. In this model, the authors adapted the work of Fox et al. 
(1998), where the authors discussed the physical resources and role of the organizational model.

Recently, Rao et al. (2012) developed an organizational ontology in order to build a knowledge map within the organization. The structure includes the flow of knowledge within the organization in the context of knowledge sharing and knowledge storage. In this model, the authors discussed the organizational resources, as in Sharma and Kweku-Muata (2008). Another aspect that is similar to Sharma and Osei-Bryson's work is that both models include business processes. However, Rao et al. (2012) discussed business processes from the organizational goals point of view and Sharma and Kweku-Muata (2008) discussed business processes from the organizational activity point of view. Most of these studies focused on the organizational structure and performance. In Izhar et al. (2013), the authors developed the organizational goals ontology that consists of organizational goals, sub-goals, and organizational data. They developed the dependency relationship for the organizational goals and dependency relationship between organizational data and organizational goals. However, they evaluate the organizational goals by identifying the organizational goals first and then they identify the organizational data that relate to the organizational goals.

Table 1 shows the results from the previous models on the organizational goals using an ontology but none of these studies focuses on structuring the big data in the context of social media. In this paper, we extend the organizational goals ontology from Izhar et al. (2013) to set up goal for social media. Therefore, we can develop the relationship between social data and goal.

TABLE 1. Previous scope of the existing models on goal based on an ontology

\begin{tabular}{|c|c|c|c|c|c|}
\hline \multirow[t]{2}{*}{ Authors } & \multicolumn{2}{|c|}{$\begin{array}{c}\text { Organizational Goals } \\
\text { Ontology }\end{array}$} & \multicolumn{2}{|c|}{ "Resources } & \multirow{2}{*}{$\begin{array}{c}\begin{array}{c}\text { Develop the } \\
\text { Relationship }\end{array} \\
\text { Big Data }\end{array}$} \\
\hline & $\begin{array}{l}\text { Organization } \\
\text { al Goals }\end{array}$ & $\begin{array}{l}\text { Sub- } \\
\text { Goals }\end{array}$ & $\begin{array}{l}\text { Organizatio } \\
\text { nal Data }\end{array}$ & $\begin{array}{l}\text { Social } \\
\text { Media }\end{array}$ & \\
\hline Fox el al. (1998) & $\checkmark$ & $\checkmark$ & $x$ & $x$ & $x$ \\
\hline $\begin{array}{l}\text { Sharma and Osei-Bryson } \\
\text { (2008) }\end{array}$ & $\checkmark$ & $\checkmark$ & $x$ & $x$ & $x$ \\
\hline Rao et al. (2012) & $\checkmark$ & $\checkmark$ & $x$ & $x$ & $x$ \\
\hline Izhar et al. (2013) & $\checkmark$ & $\checkmark$ & $\checkmark$ & $x$ & $x$ \\
\hline
\end{tabular}




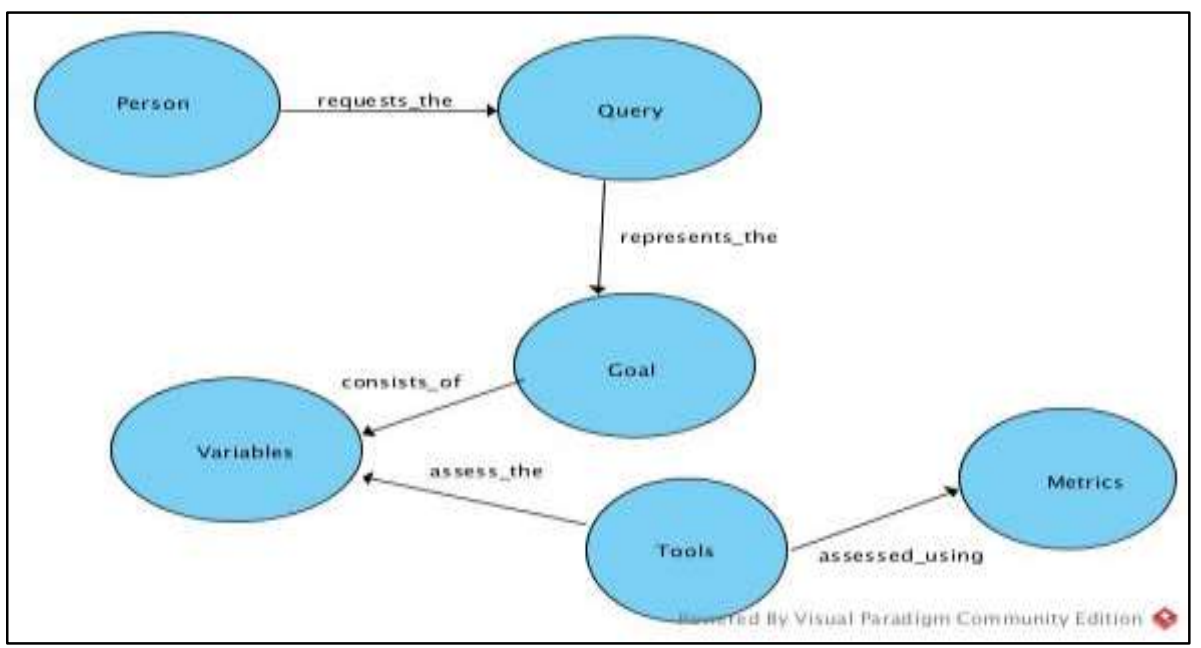

FIGURE 1. An ontology for goal query on social media using Visual Paradigm

Based on Table 1, we develop an ontology for goal query on social media, as shown in Figure 1. In Figure 1, we capture data from large database of social media by structuring this data to identify the dependency relationship of data that relate to the specific query. The relationships are proposed as follows:

- requests_the (person, query); as person requests the query.

- represents_the (query, goal); as query represents the goal.

- consists_of (goal, variables); as goal consists of variables.

- assess_the (tools, variables); as tools assess the variables.

- assessed_using (tools, metrics); as tools assessed using metrics.

\section{A Case of Twitter}

In this paper, we use Twitter as information source (Veenstra et al., 2014). Twitter is a micro blogging site in which users can post updates (tweets) to friends (followers and following) (Silva et al., 2014). We apply data from Twitter to test our ontology.

\section{Ontology for Twitter}

We select one username (@Write4Research) as an example. Write4Research is a Twitter profile that discusses on research activity and it is popular among researchers and $\mathrm{PhD}$ students. We set up a goal to examine the trend of people (followers and followings) who mention the word "PhD" in their tweets. In this example, there are three main variables in Twitter. There are other attributes that relate to these variables such as "favorites" and "message" but at this stage we only apply these variables to analyze the goal. The variables are:

- Username (@Write4Research)

- Followers

- Following

- Tweets

In this network, somewhere there might be someone who mentions the word "PhD" based on three relationships. The relationships are:

- "tweet_the" relationship.

- "replies_to" relationship.

- "mentions_the" relationship. 
The relationships show when the person in this network who tweets, mentions or replies to one another tweets about $\mathrm{PhD}$. We analyze these relationships that represent three different queries. We develop an ontology for these queries as follows:

Query 1: People who tweet about PhD tweet_the (Followers, $\mathrm{PhD}$ ), as followers tweet $\mathrm{PhD}$. tweet_the (Following, $\mathrm{PhD}$ ), as following tweet $\mathrm{PhD}$.

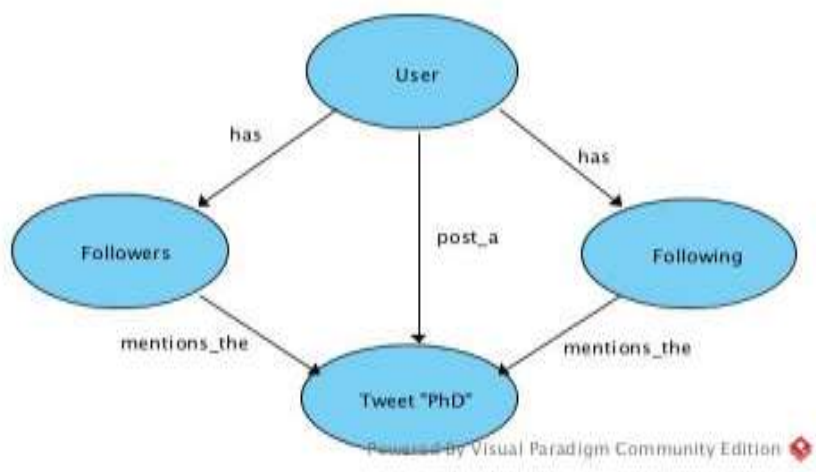

FIGURE 2. Ontology for query 1 for people who follow the tweet about $\mathrm{PhD}$

Query 2: People who reply to the tweets about PhD. replies_to (Followers, $\mathrm{PhD}$ ), as followers reply to $\mathrm{PhD}$. replies_to (Following,PhD), as following replies to $\mathrm{PhD}$.

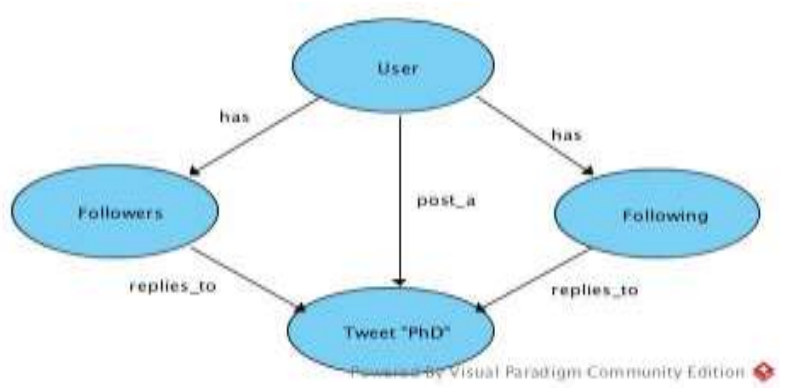

FIGURE 3. Ontology for query 2 for people who reply to the tweet about $\mathrm{PhD}$

Query 3: People who mention the tweets about PhD. mentions_the(Followers, PhD) as followers mention the PhD. mentions_the(Following, $\mathrm{PhD}$ ) as following mentions the $\mathrm{PhD}$.

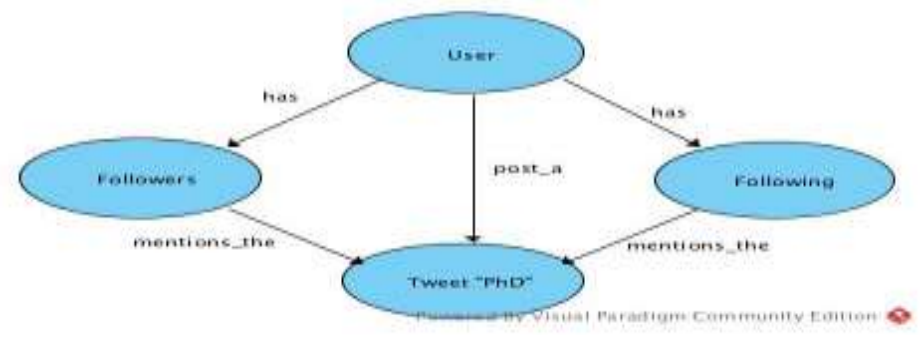

FIGURE 4. Ontology for query 3 for people who mention the tweet about $\mathrm{PhD}$ 


\section{Sampling and Data Collection}

In order to identify participants, we used the sampling pool of Twitter that appears in the NodeXL, a software tool that imports data from outside data providers. It is an extendible toolkit for network overview, discovery and exploration implemented as an add-in to the Microsoft Excel 2007 spreadsheet software. NodeXL is applied to retrieve data from social media and import this data. NodeXL demonstrates data analysis with a social media data sample drawn from an enterprise intranet social network. We apply NodeXL to visualize the ontology for three different queries. When it comes to collecting, computing, analyzing, and acting on social data, technical challenges are quite different because number of social data always increases and makes it difficult to evaluate. For example, today data might be important but tomorrow this data might not be important anymore. Therefore, we filter this data based on certain date and for each relationship.

\section{Filter}

This section will provide steps to demonstrate how we filter data from large amount of data from the social media to allow us to evaluate specific query in relation to the goals. These preferences are used to configure the steps in filtering the data from Twitter using NodeXL.

1. Import from Twitter users network.

1.1. It optionally clears the NodeXL workbook, then gets the network of specified Twitter users.

2. Specify the Twitter users with specific username.

2.1. We are interested in username @Write4Research.

3. Import basic network plus followers and following who reply, mention and tweet.

3.1. Limit it to 100 recent tweets per user.

4. Import from Twitter search network.

4.1. It optionally clears the NodeXL workbook, then get the network of people who tweet certain specified word.

5. Search for the tweets that match the specific query.

5.1. We search for PhD.

6. Import basic network to specifically show who replied or mentioned in the tweets.

6.1. Limit to 100 tweets.

7. Filter by relationships (tweets, mentions and replies).

The step-by-step guideline explains how we select data from huge volume of social data that relate to the query. Using NodeXL as a tool to capture this data, this guideline provides systematic steps for domain experts to capture which data they want to evaluate to assist their decision-making in relation to the organizational goals. However, in other case, domain experts might use different tools to capture this data and the process to identify relevant data might be different.

\section{ANALYSIS AND RESULTS}

In this case study, we examine user trends on Twitter by visualizing the relationships in Write4Research's network. Fig. 5 shows the result for query 1. The results show the relationship of people who start the tweet about PhD. Fig. 5 
shows that there are not many people who tweet to $\mathrm{PhD}$ topic on the selected date.

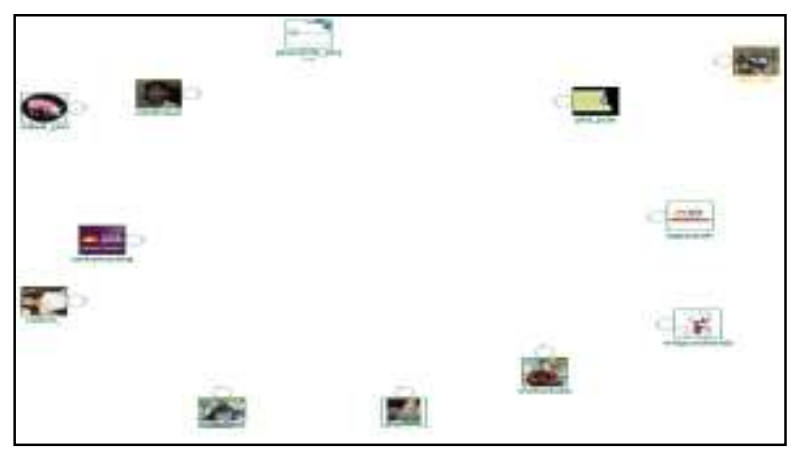

FIGURE 5. Query 1 for people who tweet about $\mathrm{PhD}$

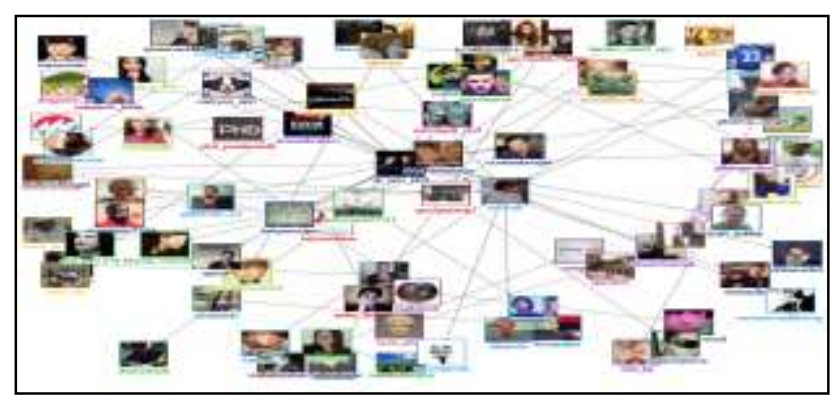

FIGURE 6. Query 2 for people who mention (retweet) about PhD

Fig. 6 shows the result for query 2, that shows the relationship of people who retweet about $\mathrm{PhD}$. The graph shows the relationship that linked to different profiles. Fig. 6 shows the number of people who retweet to PhD topic on the selected date.

Fig. 7 shows the result for query 3, that shows the relationship of people who reply to the tweet. The graph also shows the relationship that linked to different profiles. There are not many people who reply to the tweet on the selected date.

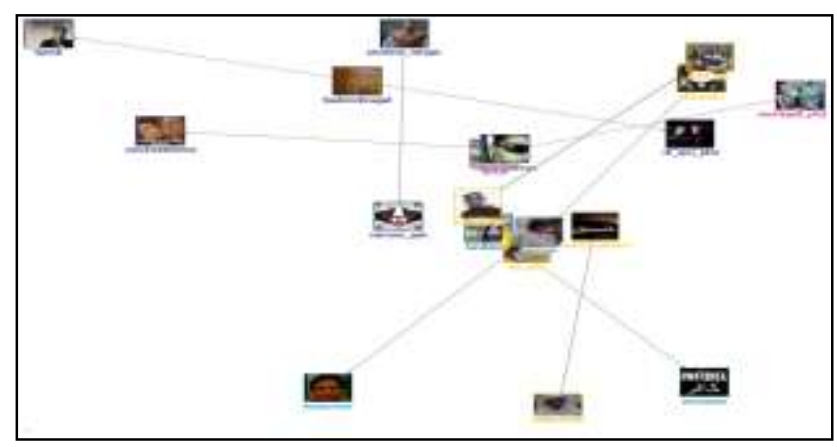

FIGURE 7. Query 3 for people who reply to the tweet about $\mathrm{PhD}$

The graphs show interesting results for these three relationships. The results show that people in Write4Research's network prefer to retweet about PhD, as 
shown in Fig.6. It shows that they are interested to share about this topic in their network. We come out with this decision because majority of Write4Research's followers are researchers.

\section{CONCLUSION}

A unique contribution of this paper is its perspective on how to develop the relationship between social data and goal. The relationship helps the process to identify the goal, identify the relevant data that relate to the goal and analyze this relationship to retrieve relevant information to support decision-making. The paper contributes to:

- Flexibly identify the goal

- Flexibly identify the dependency relationship

- Flexibly analyze the data

Social media such as Facebook and Twitter have become an indispensable part of our lives. In this paper, we have described the main features of ontology when developed the relationship for social data in relation to the goal. In addition, we have proposed an alternative approach to capture social data using NodeXL. We extend the application of the ontology for social media in relation to the goal by developing the relationship for this social data. This paper enables researchers to classify and evaluate existing research, to design scientific research, to identify the gaps and weaknesses prior to future research directions.

\section{LIMITATIONS AND RECOMMENDATIONS}

This study has potential limitations and scope for further improvement. This study conducted a case study design, however in future other research designs must be used to gather more insights.

\section{REFERENCES}

Almeida, Mauricio B., and Ricardo R. Barbosa. 2009. Ontologies in knowledge management support: A case study. Journal of the American Society for Information Science and Technology 60, no. 10: 2032-2047. D0I: 10.1002/asi.21120

Berber, Martin, Enrico Graupner, and Alexander Maedche. 2014. The information panopticon in the big data era. Journal of Organization Design 3, no. 1: 14-19. 10.7146/jod.9736

Cho, Joonmyun, Soonhung Hana, and Hyun Kimb. 2006. Meta-ontology for automated information integration of parts libraries. Computer-Aided Design 38, no. 7, 713-725. DOI: 10.1016/j.cad.2006.03.002

Damianos, Laurie E., Donna L. Cuomo, and Stan Drozdetski. 2011. Handshake: A case study for exploring business networking for enterprise, inside and out. In Lecture notes in computer science. New York, NY: Springer-Verlag. DOI: $10.1007 / 978-3-642-21796-8 \_17$

Davenport, Tom, and Jill Dyché. 2013. Big data in big companies. International Institute for Analytics, Portland, OR.

Damianos, Laurie E., Donna Cuomo, John Griffith, David M. Hirst, and James Smallwood. 2007. Exploring the adoption, utility and social influences of social bookmarking in a corporate environment. Paper presented at the International Conference on System Sciences, Hawaii, HI. DOI: 10.1109/hicss.2007.219

Doreian, Patrick. 2001. Causality in social network analysis. Sociological Methods \& Research 30, no. 1: 81-114. D0I: $10.1177 / 0049124101030001005$

Fox, Mark S., Mihai Barbuceanu, and Michael Gruninger. 1996. An organisation ontology for enterprise modeling: Preliminary concepts for linking structure and behaviour. Computers in Industry 29, no. 1-2: 123-134. D0I: 10.1016/0166-3615(95)00079-8 
Fox, Mark S., Mihai Barbuceanu, Michael Gruninger, and Jinxin Lin. 1998. An organization ontology for enterprise modelling. In Simulation organizations: Computational models of institutions and groups eds, Michael Prietula, Kathleen Carley, and Les Gasser, ch. 131-152. Massachusetts, MA: MIT Press.

Galbraith, Jay R. 2014. Organization design challengers resulting from big data. Journal of Organization Design 3, no. 1: 2-13. DOI: $10.7146 /$ jod.8856

Gandomi, Amir, and Murtaza Haider. 2015. Beyond the hype: Big data concepts, methods and anlytics. International Journal of Information Management 35, no. 2: 137-144. DOI: 10.1016/j.ijinfomgt.2014.10.007

Gangadharbatla, Harsha, Laura F. Bright, and Kelty Logan. 2014. Social media and news gathering: tapping into the millennial mindset. The Journal of Social Media in Society 3, no. 1: 45-63. DOI: 10.1080/17517575.2010.513014

Ghani, Norjihan A., and Siti Syahidah M. Kamal. 2015. A Sentiment-based filteration and data analysis framework for social media. Paper presented at the 5th International Conference on Computing and Informatics ICOCI (pp. 632637), Istanbul, TU, August 11-13.

Governatoria, Guido, and Renato Iannellab. 2011. A modeling and reasoning framework for social networks policies. Enterprise Information Systems 5, no. 1: 145-167.

$\mathrm{He}, \mathrm{Wu}$, Shenghua Zhab, and Ling Li. 2013. Social media competitive analysis and text mining: A case study in pizza industry. International Journal of Information Management 33, no. 3: 464-472. D0I: 10.1016/j.ijinfomgt.2013.01.001

Holtzblatt, Lester, Jill L. Drury, Daniel Weiss, Laurie E. Damianos, and Donna Cuomo. 2013. Evaluating the uses and benefits of an enterprise social media platform. Journal of Social Media for Organizations 1, no. 1: 1-21.

Huang, Tao, Liang Lan, Xuexian Fang, Peng An, Junxia Min, and Fudi Wang. 2015. Promises and challenges of big data computing in health sciences. Big Data Research 2, no. 1: 2-11. DOI: 10.1016/j.bdr.2015.02.002

Izhara, Tengku A.T., Torab Torabi, Bhatti M. Ishaq, and Fei Liua. 2013. Recent developments in the organization goals conformance using ontology. Expert Systems with Applications 40, no. 10: 4252-4267. DOI; 10.1016/j.eswa.2013.01.025

Jin, Xiaolong., Benjamin W. Waha, Xueqi Chenga, Yuanzhuo Wanga. 2015. Significance and challenges of big data research. Big Data Research, 2, no. 2: 59-64. DOI: 10.1016/j.bdr.2015.01.006

Kaplan, Andreas M., and Michael Haenlein. 2010. Users of the worl, united! The challenges and opportunities of Social Media. Business Horizons 53, 1: 59-68. D0I: 10.1016/j.bushor.2009.09.003

Keckley, Paul H. 2010. Social networks in health care: Communication, collaboration and insights. URL: http://goo.gl/bVCbkd (accessed on April 27, 2016).

Kontopoulos, Efstratios, Christos Berberidis, Theologos Dergiades, and Nick Bassiliades. 2013. Ontology-based sentiment analysis of twitter posts. Expert Systems with Applications 40, no. 10: 4065-4074. D0I: 10.1016/j.eswa.2013.01.001

Mansingh, Gunjan, Kweku-Muata Osei-Bryson, and Han Reichgelt. 2009. Building ontology-based knowledge maps to assist knowledge process outsourcing decisions. Knowledge Management Research and Practice 7, 37-51. D0I: 10.1057/kmrp.2008.37

Park, Namsu, Kerk F. Kee, and Sebastián Valenzuela. 2009. Being immersed in social networking environment: Facebook groups, uses and gratifications, and social outcomes. Cyber Psychology \& Behavior 12, no. 6: 729-733. DOI: $10.1089 / \mathrm{cpb} .2009 .0003$

Qualman, Erik. 2009. Socialnomics how social media transforms the way we live and do business. Hoboken, US: Wiley John \& Sons, Inc.

Raacke, Raacke., and Jennifer Bonds-Raacke. 2008. MySpace and Facebook: Applying the uses and gratifications theory to exploring friend-networking sites. CyberPsychology \& Behavior 11, no. 2: 169-174. DOI: $10.1089 / \mathrm{cpb} .2007 .0056$

Rao, Lila, Gunjan Mansinghb, and Kweku-Muata Osei-Brysonc. 2012. Building ontology based knowledge maps to assist business process re-engineering. Decision Support Systems 52, no. 3: 577-589. DOI: 10.1016/j.dss.2011.10.014

Rao, Lila., Gunjan Mansinghb, Kweku-Muata Osei-Brysonc. 2009. An approach for ontology development and assessment using a quality framework. Knowledge Management Research and Practice 7, no. 3: 260-276. D0I: $10.1057 / \mathrm{kmrp} .2009 .12$ 
Roth, Camille., and Jean-Philippe Cointet. 2010. Social and semantic coevolution in knowledge networks. Social Networks 32, no. 1: 16-29. DOI: 10.1016/j.socnet.2009.04.005

Safko, L, and Kevin Pierce. 2009. The social media bible: Tactics, tools, and strategies for business success. Hoboken, US: Wiley John \& Sons, Inc. .

Sharma, Sumana, and Kweku-Muata Osei-Bryson. 2008. Organization-ontology based framework for implementing the business understanding phase of data mining projects. Paper presented at the International Conference on System Sciences, Hawaii, HI. DOI: 10.1109/hicss.2008.339

Silva, Nadia F.F.D., Eduardo R. Hruschka, and Estevam R. Hruschka Jr. 2014. Tweet sentiment analysis with classifier ensembles. Decision Support Systems, 66, 170-179. DOI: 10.1016/j.dss.2014.07.003

Valaski, Joselaine., Andreia Malucelli, and Sheila Reinehr. 2012. Ontologies application in organizational learning: A literature review. Expert Systems with Applications 39, no. 8: 7555-7561. D0I: 10.1016/j.eswa.2012.01.075

Valiente, Maria-Cruz, Garcia-Barriocanal, E., \& Sicilia, M.-A. (2012). Applying an ontology approach to IT service management for business-IT integration. Knowledge-Based Systems, 28, 76-87. D0I: 10.1016/j.knosys.2011.12.003

Veenstra, Aaron S., Narayanan Iyer, Mohammad D. Hossainb, and Park Jiwoo. 2014. Time, place, technology: Twitter as an information source in the Wisconsin labor protests. Computer in Human Behavior 31, 65-72.

Zhi, Qiu, Zhao-Wen, Lin, and Yan, Ma. 2011. Research of Hadoop-based data flow management system. The Journal of China Universities of Post and Telecommunications 18, no. 2: 164-168.

— This article does not have any appendix. - 